\title{
“Crack down on the celebrity junkies": does media coverage of celebrity drug use pose a risk to young people?
}

\author{
Rachel L. Shaw* \\ Aston University, Birmingham, UK \\ Claire Whitehead \\ Aston University, Birmingham, UK
}

David C. Giles

University of Winchester, Winchester, UK

*School of Life and Health Sciences, Aston University, Birmingham, B4 7ET, UK. Tel: +44(0)121 2044050; Fax: +44(0)121 2044090; Email: r.l.shaw@aston.ac.uk.

\begin{abstract}
This study analysed news media content to examine the role played by celebrity drug use in young people's perceptions of drug use. We know that young people have access to discourses of drug use through music and other media which may emphasise short term gains (of pleasure or sexual success) over longer term health and social problems. This study goes beyond a simple modelling approach by using Media Framing Analysis (MFA) to take an in-depth look at the messages themselves and how they are 'framed'. New stories about Amy Winehouse's drug use were used and we conducted focus groups with young people asking them questions about drugs, celebrity and the media. Frames identified include: ‘troubled genius', 'losing patience' and 'glamorization or gritty realism'. Initially, the press championed Winehouse's musical talent but soon began to tire of her recklessness; the participants tended to be unimpressed with Winehouse's drug use, characterising her as a promising artist who had 'gone off the rails'. Young people were far more critical of Winehouse than might be expected demonstrating that concerns about the influence of celebrity drug use and its impact on future health risk behaviour among young people may have been over-simplified and exaggerated. This study illustrates the need to understand young people and their frames of reference within popular culture when designing drug awareness information relevant to them. Furthermore, it indicates that critical media skills analysis may contribute to health risk education programmes related to drug use.
\end{abstract}

Keywords: media framing; health risk behaviour; young adults; celebrity; qualitative research.

Short title: Celebrity drug use and young people

Final version of published article: Shaw, R.L., Whitehead, C. \& Giles, D.C. (2010). "Crack down on celebrity junkies": does media coverage of celebrity drug use pose a risk to young people? Health, Risk \& Society, 12(6), 575-589. 
In the 24 hour news culture of contemporary Western society, we are never far away from stories warning us of risks to our health. More than ever before, the media provide a forum in which risk messages are conveyed that serve to stimulate narratives of risk within society. In a recent study exploring current concerns among UK adults, risks to health, societal risks including crime, drugs and antisocial behaviour, and risks to family were reported most frequently (Hawkes, Houghton and Rowe, 2009). The focus of this study is drug abuse; more specifically, we investigate news media coverage of celebrity drug abuse and how such stories are received by young people. This study is set within the context of continued concern that negative roles models - celebrated in the press lead to the heightened risk that young people will themselves engage in health risk behaviours such as drug use.

Anxieties over young people’s modelling of celebrity behaviour stem partly from the application of social learning theory to 'media effects' (Bryant and Zillmann, 2002), with its origins in Bandura’s famous ‘Bobo doll’ studies (Bandura, Ross and Ross, 1961, 1963) and subsequent research in the experimental tradition. Today, while cultural scholars are highly critical of the 'effects' tradition (see, for example, Gauntlett, 2005), most contemporary communication scientists do not solely accept simple modelling effects as explanations for media influence (see for example, Brown, Basil and Bocarnea, 2003).

Nevertheless, modelling theory has a powerful grip on the public imagination. Media attention on drug-taking by celebrities has been widely criticised in recent years by organizations as diverse as the Girl Guides and the United Nations, whose International Narcotics Control Board has claimed that "celebrity drug offenders can profoundly influence public attitudes, values and behaviour towards drug abuse, particularly among young people who have not yet taken a firm and fully informed Final version of published article: Shaw, R.L., Whitehead, C. \& Giles, D.C. (2010). "Crack down on celebrity junkies": does media coverage of celebrity drug use pose a risk to young people? Health, Risk \& Society, 12(6), 575-589. 
position on drug issues.” (INCB, 2008, p.11). In short, there is a concern that young people will model their behaviour on celebrity personalities thereby increasing the chances that they themselves will indulge in health risk behaviours such as taking drugs.

In 2008, the television company Sky conducted a poll in which singersongwriter Amy Winehouse was voted the “ultimate heroine” by people aged under 25 (NME, 2008). Winehouse is a young musician famous for her 'retro' style both in terms of her beehive hairstyle and her music which is heavily influenced by blues and Motown. She has attracted critical acclaim winning five Grammy awards and three nominations for Ivor Novello awards. However, more recently she has attracted a good deal of notoriety following media reports of prosecution and rehabilitation for drug use, and is frequently cited in the media as having potentially harmful influences on her young admirers.

Drug abuse has long been an integral component of the deviant lifestyle celebrated in many forms of popular music; indeed it has profoundly influenced the creative process of rock music in particular, and music business practice itself (NapierBell, 2002). Social concern about the corrupting influence of rock music and glamorous celebrity lifestyle has never truly abated, with each generation seemingly producing a deviant fringe of notorious figures who attract adverse media attention (see Forsyth and Barnard, 1998, for a comparison of 1960s and 1990s artists).

The influence of popular music on adolescent behaviour has attracted a certain amount of research interest (albeit far less than the influence of film, television, or video games), with particular focus on the association of particular music genres with rebellious behaviour, and the corrupting influence of certain lyrical content (KnoblochWesterwick, Musto and Shaw, 2008). Much social psychological research has taken as its theoretical base the process of cognitive 'priming' (Berkowitz, 1984), whereby Final version of published article: Shaw, R.L., Whitehead, C. \& Giles, D.C. (2010). "Crack down on celebrity junkies": does media coverage of celebrity drug use pose a risk to young people? Health, Risk \& Society, 12(6), 575-589. 
'exposure’ to certain words creates associations with thematically-related cognitions. Experimental research has found that, under laboratory conditions, listening to violent rap music can trigger aggressive thoughts (Anderson, Carnagey and Eubanks, 2003), while listening to lyrics about suicide can elicit suicide-related themes in free composition (Martin, Clarke and Pearce, 1993); likewise, listening to prosocial lyrics can prime prosocial cognitions (Greitemeyer, 2009).

A number of studies have focused specifically on drug-related lyrics in popular music. Primack, Dalton, Carroll, Agarwal and Fine (2008) found explicit references to drugs or alcohol in a third of the lyrics sampled and Fernandez (2003) identified indirect drug allusions (e.g., "estoy borracho de amor” - "I am drunk with love”) which emphasize a romantic association to feeling intoxicated. However, Forsyth and Barnard (1998) found little evidence that such lyrics are related to preferred music choice. A more convincing finding is that of Miranda and Claes (2004), who found a relationship between deviant behaviour in general (including cannabis use) and a preference for French language rap in a bilingual French-Canadian sample. The authors argue that cannabis use is a frequent theme in French rap and that the linguistic context made this association particularly salient. Taking a discursive approach, Markert (2001) examined over 800 songs across 40 years with explicit reference to drugs and argued that the majority portrayed drug use in a negative light, particularly in relation to heroin and cocaine, and that such negative portrayals had actually increased during the 1990s. He suggests that this trend is reflected in increasingly critical attitudes towards drug use by young people, and even that "the current negative assessment of drugs by younger musicians may serve to waylay drug involvement” (Markert, 2001, p. 216).

In addition to drug references in pop lyrics is the concern over the influence of drug use by celebrities. In one study (Boon and Lomore, 2001) it was found that 75 per Final version of published article: Shaw, R.L., Whitehead, C. \& Giles, D.C. (2010). "Crack down on celebrity junkies": does media coverage of celebrity drug use pose a risk to young people? Health, Risk \& Society, 12(6), 575-589. 
cent of young adults have a strong attraction to a celebrity at some point in their lives, with musicians and movie stars being the most popular recipients of adulation. In Boon and Lomore's study, the majority of participants claimed that their idols had a positive influence on their lives, yet the prevailing concern is that celebrities act as role models for antisocial or otherwise undesirable behaviour.

The present study focuses on Amy Winehouse as a figure around which discourses of drugs, and 'bad behaviour' in general, circulate widely in the UK media. In the authors’ views, modelling and cognitive priming offer only a partial explanation of how media influence their audiences. We believe it is important to consider other processes. Firstly, it is important to study thoroughly the media phenomenon of interest, because the 'message' imparted by media is rarely as simple as is sometimes portrayed in laboratory studies. Here, we advocate the importance of studying the 'framing' processes of the media (Shaw and Giles, 2009; Giles and Shaw, 2009). Secondly, it is also important to consider the multitude of 'parasocial' relationships that exist for media users and media figures, such as celebrities (Giles, 2002). Celebrities are meaningful figures in the lives of young people in particular, and elicit a much more complex set of responses than simple imitation.

As a media figure, Amy Winehouse makes a particularly interesting object of study because she cuts a rather unusual figure in the history of drug-taking in rock music. To begin with, she is female, while the vast majority of rebellious figures from music have traditionally been male (although in recent years female celebrities have featured highly in media coverage of drug-taking and other excesses). Although a young woman (b. 1983), her musical style is fundamentally rooted in pre-1970 blues, jazz and soul music, which gives her a broader fan base than traditionally rebellious musical

Final version of published article: Shaw, R.L., Whitehead, C. \& Giles, D.C. (2010). "Crack down on celebrity junkies": does media coverage of celebrity drug use pose a risk to young people? Health, Risk \& Society, 12(6), 575-589. 
figures, who have typically appealed to an exclusively young audience. Nevertheless, as the Sky poll suggests, she has cultivated a large following among younger fans.

Winehouse's drug use, and its resulting health and legal problems, have been widely chronicled in the British media, and part of the present study constitutes an analysis of these media reports. They are also referred to extensively in her own lyrics. Addicted, from her second (2006) album Back in Black (its own title a reference to alcohol-induced blackout), describes extensively the glories of 'weed' and 'draw', while from the same album Rehab, with its hook line "They tried to make me go to rehab but I said no, no, no", explicitly relates the singer's own dilemma over clinical treatment for her alcoholism.

While these lyrics hardly fall into the category of romanticised drug use (Fernandez, 2003), they might be regarded as typical of the type of lyrics analysed by Markert (2001), demonstrating a degree of ambivalence towards drug use, balancing short-term highs with long-term health issues. Alternatively, they might be interpreted as portraying drug use as a casual, everyday occurrence for a young person. The latter track also features repeated references to a 'Daddy' figure, which may or may not refer to the singer's father, who has been quoted frequently in the UK press making critical comments about his daughter's lifestyle and health condition. This degree of family involvement is another characteristic that marks Winehouse as unusual among rebel musicians.

In addition to an analysis of the media portrayal of Winehouse, the present study also includes an analysis of focus groups conducted with teenagers, the group who might be thought to be at the highest risk from the corrupting influence of badly behaved celebrities.

Final version of published article: Shaw, R.L., Whitehead, C. \& Giles, D.C. (2010). "Crack down on celebrity junkies": does media coverage of celebrity drug use pose a risk to young people? Health, Risk \& Society, 12(6), 575-589. 


\section{Method}

There are two parts to this study: first, a Media Framing Analysis (Shaw and Giles, 2009) of UK newspaper stories about Amy Winehouse; second, focus groups with young people analyzed using thematic analysis (Braun and Clarke, 2006).

Ethical approval was granted by the University in which the study was based and permission was granted by the Principal to recruit young people from a nearby Sixth Form College for students aged 16 to 19 sitting UK examinations at AS and A level (entry qualifications for higher education).

\section{Media Framing Analysis}

A search was conducted on Lexis-Nexis (a database of newspaper content dating back to 1981) using the keywords “Amy Winehouse”, “addiction” and “drug abuse”. The search was limited to UK national newspapers published between July 2007 and May 2008. This period includes coverage of a number of significant events in Winehouse's career, including an evening on which she was hospitalised following a collapse on stage due to a suspected drug overdose, the release of a video allegedly featuring Winehouse smoking crack cocaine, her admission to a Rehabilitation Clinic, her winning five Grammy awards, receiving nominations for three Ivor Novello awards, her arrest following an alleged assault (for which she was later charged), and her arrest for suspicion of possession of drugs (no charges were subsequently brought against her).

Using Lexis-Nexis we identified 112 records of which 35 were considered relevant (see Table 1 for details). Records included were news articles, features or commentaries focusing on aspects of Winehouse's drug use; letters were excluded as were articles which only briefly mentioned Winehouse but not her drug use. Content of these articles was then analysed according to the principles described by Shaw and Final version of published article: Shaw, R.L., Whitehead, C. \& Giles, D.C. (2010). "Crack down on celebrity junkies": does media coverage of celebrity drug use pose a risk to young people? Health, Risk \& Society, 12(6), 575-589. 
Giles (2009) for Media Framing Analysis (MFA). This involved first reading through the articles to identify a timeline of events that triggered stories about Winehouse's drug use, identifying the "news pegs” on which later stories hang (Cooper and Yukimura, 2002). Second, the dramatis personae, or key characters, in Winehouse's story were examined in relation to the characters with which the reader was invited to identify (Entman, 1993). Next, we determined the narrative form of news articles and identified instances of rhetorical devices, such as emotive language or metaphor (Billig, 1987). Finally, we considered the extent to which stories of Winehouse drew on generalizations or media templates (Kitzinger, 2000) in the framing of stories of celebrity drug use.

Taking each of these aspects of the texts into account, we then organised the articles into themes which represent the different ways in which media messages about Winehouse were framed. In short, a frame refers to the general media package that provides “a central organizing idea ... for making sense of relevant events” (Gamson and Modigliani, 1989; p.3). By framing a story in a particular way, news articles can convey one particular message rather than another; in MFA the objective is to critically analyse the dominant ways in which media messages are conveyed to identify the psychological mechanisms that may be evoked by that framing process.

- Table 1 here -

\section{Focus Groups with Young People}

Four focus groups were conducted, each consisting of four to six participants (a total of 20 took part). Volunteers were students at a UK Sixth Form College and all aged 17; two were South Asian and the remainder White British. An aide mémoire informed by the MFA guided the discussions and included several news stories to stimulate debate.

Final version of published article: Shaw, R.L., Whitehead, C. \& Giles, D.C. (2010). "Crack down on celebrity junkies": does media coverage of celebrity drug use pose a risk to young people? Health, Risk \& Society, 12(6), 575-589. 
Open-ended questions related directly to the stories but also more generally about celebrity drug use were asked.

The discussions were transcribed verbatim and analysed using thematic analysis (Braun and Clarke, 2006). The analysis began with a search for initial codes: features that seemed relevant to the research question were coded and then data attributed to each code were further scrutinised and potential links between codes were explored. These code clusters were then organised into themes. The findings of the MFA were then synthesised with the focus group findings in order to examine the 'fit' of framing themes with discussion themes. The thematic fit was sufficiently good to provide a broad structure for the following analysis, although at times actual opinions diverged both between media and focus groups, and between focus group members themselves. Our analysis takes this divergence into account rather than presenting an artificiallyglossed model.

\section{Results}

The three major themes identified are presented in series with illustrations from both the media and focus groups. These are: Troubled genius, Losing patience, and Glamorization or gritty realism.

\section{Troubled genius}

This dominant theme casts Winehouse firmly within a long tradition of creative and artistic individuals whose achievements are offset by a colourful lifestyle and turbulent private life. Although the 'news peg' for most articles was identified as a drug-related incident (such as the on-stage collapse in July 2008), most sources acclaimed Winehouse's talent and framed her as a breath of fresh air by contrast with the "bland Final version of published article: Shaw, R.L., Whitehead, C. \& Giles, D.C. (2010). "Crack down on celebrity junkies": does media coverage of celebrity drug use pose a risk to young people? Health, Risk \& Society, 12(6), 575-589. 
creations of record company executives” (A6) typically deriving from television talent shows, a phenomenon experienced recently in many parts of the world. Winehouse's status as a talented individual is partly related to her revival of 'classic' popular music forms such as Motown, which together with her distinctive appearance constitutes the making of a "true star" (A6):

At 23, jazz singer-songwriter Amy Winehouse may be the hottest female singing talent in the world ... With her trademark towering beehive, Cleopatra eyeliner and sailors' tattoos adorning her upper arms, she is Disney-like in terms of being instantly recognisable. (A3)

During the period analysed, something of a shift in emphasis was observable.

Winehouse's behaviour and distinctive style are characterised in the earlier reports as quirkiness and mischievous non-conformism. As time elapses and stories of Winehouse's "missed gigs, the spitting and the vomiting, the booze and the brawling” (A2) become more frequent, the tone changes from one of tolerant indulgence to one of serious concern for her health. "Why isn’t anyone saving Amy?” (A11) asked one article, followed by repeated appeals to Winehouse to check into a rehabilitation programme and eventually move on to further success. Even Keith Richards of the Rolling Stones, a figure long associated with heavy drug use, was quoted as saying "She isn’t going to be around long unless she sorts herself out pretty quick . . . she needs to get smart” (A32).

However, the young people who spoke to us in focus groups did not participate in this media drive to "save Amy”. Although they recognised Winehouse's success, their accounts were critical of her and reflected a cynicism we might not have expected from those who supposedly represent part of Winehouse's key audience. They speculated as to whether stories of drug excesses were "exaggerated” (Bernie; FG1) because "the media always go over the top about stuff [and] they do make things worse"

Final version of published article: Shaw, R.L., Whitehead, C. \& Giles, D.C. (2010). "Crack down on celebrity junkies": does media coverage of celebrity drug use pose a risk to young people? Health, Risk \& Society, 12(6), 575-589. 
(JD; FG2). Nevertheless, there was a sense of frustration from some discussants that Winehouse was “wasting her talent” (Courtney; FG3).

The ambivalence felt by many of the focus group discussants was partly related to uncertainty over the merits of her music. There was a clear sense that Winehouse does not really fit a recognised mould as a 'mainstream pop star' and that her habit of chronicling her lifestyle in her lyrics may be partly to blame for the media interest:

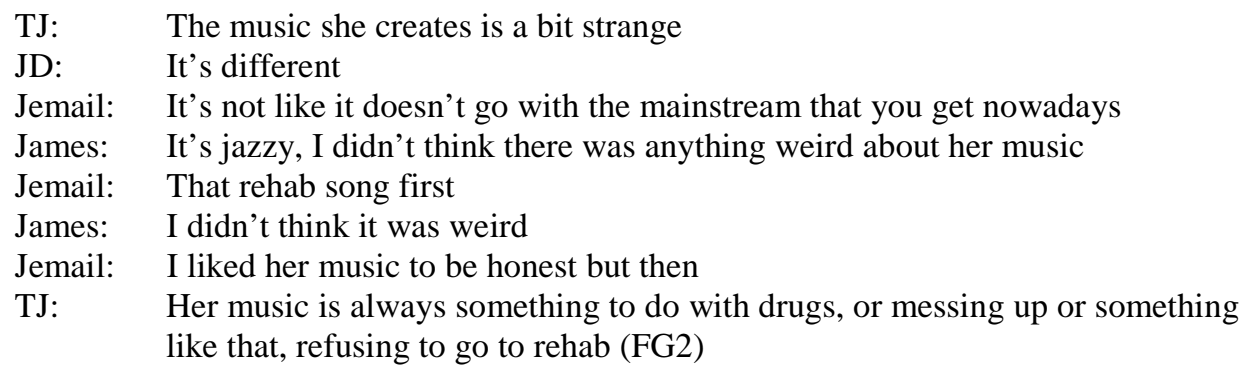

Here we could see an oblique distinction between the media coverage of Winehouse and the way she is understood by this young audience. The extract above indicates the young people’s awareness of a potential ploy used purposively by Winehouse. They are suggesting that by including autobiographical lyrics which refer explicitly and implicitly to her excessive use of alcohol and drugs that Winehouse is outside of the “mainstream” and probably less naïve than the frames identified in this early media coverage. Many of the press articles constructed a protective and moralistic frame that ultimately absolves Winehouse of personal responsibility for her situation, blaming instead outside forces such as drug dealers and her unfortunate choice of husband (Blake Fielder-Civil, later jailed for assault), and even poor parenting (her mother is quoted in one article as blaming her father's absence during her childhood for her behaviour). Richard Madeley and Judy Finnegan, a TV-presenting married couple, exemplify this frame in their article for the Daily Express (A16):

The girl has fallen by the wayside and into the rapacious arms of dealers and users and parasites of the most evil kind ... writhing in the horrible squalor and degradation of hard Final version of published article: Shaw, R.L., Whitehead, C. \& Giles, D.C. (2010). "Crack down on celebrity junkies": does media coverage of celebrity drug use pose a risk to young people? Health, Risk \& Society, 12(6), 575-589. 
drugs use ... Amy is just 24. Twenty four! Children, grandchildren; a full life well lived all prospects now very nearly beyond her reach.

The emotive language ("evil”, "horrible squalor") in this extract clearly displays an attempt to prompt an emotional reaction from readers. It also represents the catastrophizing that is common in British "red tops" that focus group participants also related to. However, the young discussants were more cynical in their reaction to the stories and freely identified potential motivations for Winehouse receiving such substantial media coverage:

It's probably got her a few record sales. (Alex; FG1)

She might take drugs 'cause it's a pretty good publicity stunt. You take drugs and you get a lot of publicity. No-one will forget who Amy Winehouse is now from my generation. (Sam; FG4)

Again this demonstrates awareness among these young people that the relationship between celebrities and the media is not always straightforward. In the extract above they suggest that Winehouse actively courted the media and invited her infamy not simply through her drug-taking behaviour but also her reference to it in her songs.

\section{Losing patience}

The second theme concerns a sense of fatigue that both the media coverage and the young people in our sample have often expressed towards Winehouse. Rather than empathy for her troubles, they construct her as an 'Other' in a way that distances her from them. When the study took place Winehouse was in her early twenties and the participants in this study were aged 17 . This is a significant age gap in such a transformative stage in life. While the young participants may not be rich pop stars, as students they are a group considered to be at risk from peer pressure and the influence of celebrities who they may view as role models. However, the discussants seemed to Final version of published article: Shaw, R.L., Whitehead, C. \& Giles, D.C. (2010). "Crack down on celebrity junkies": does media coverage of celebrity drug use pose a risk to young people? Health, Risk \& Society, 12(6), 575-589. 
be torn between, on the one hand, a punitive attitude toward Winehouse (reflecting a criminalization discourse of drug use) and a more person-centred, self-help approach, drawing on discourses of addiction and illness. First, we can see agency attributed to Winehouse together with a suspicion that she does not want to quit:

It's not like she doesn't want to do it obviously she does want to do it. There's no point trying to help her when it's her own choice. (Sam; FG4)

She's been like given more media attention for doing it so there's no motivation [to stop]. (Adam; FG1)

Second, we identified familiar patterns of self-help advice and a potential lack of agency in the discourse of addiction:

She can only change if she wants to. (Mazy; FG1)

She might have done it and then think I want to stop now but she can't physically stop.

That's why she needs help but the media are putting it in her face all the time. (Bruce; FG4)

In an attempt to find reasons for Winehouse's behaviour that make sense to them, these young people draw upon cultural practices related to drug use, such as the need to first admit an addiction from Twelve Step Program fame and the perceived inability to "physically stop" without seeking help. This illustrates the need to fill in the gaps in the stories published in newspapers in order to rationalise Winehouse's self-destructive behaviour.

Notwithstanding the empathy displayed above, the tone in some discussions is one of lost patience toward Winehouse, the media and the public. Indeed, some participants wondered whether "people go to watch her fall over and stuff” (Adam; FG1) instead of for her music:

Alex: $\quad$ She's more famous, known for her drugs than her music

Adam: People find it more interesting like her falling over and with her big hair and stuff, smoking through a crack pipe and stuff Alex: $\quad$ Exactly, than she is for her own songs

Bernie: Yeah, it's become a bit too much of a big part of how she's portrayed (FG1)

Final version of published article: Shaw, R.L., Whitehead, C. \& Giles, D.C. (2010). "Crack down on celebrity junkies": does media coverage of celebrity drug use pose a risk to young people? Health, Risk \& Society, 12(6), 575-589. 
This lost patience is also present in the media coverage as Winehouse is variably described as "just another car crash celebrity" (A34), a "self-pitying waster" (A14) who has become "The nation’s biggest crashing bore” (A34). The same newspaper which printed Richard and Judy's sentimental story of the innocent Winehouse powerlessly battling against the evil drug dealers also appealed in a headline - “Amy, just disappear in a puff of smoke” (A14) which demonstrates the fickle nature of the media's relationship with celebrities.

When Winehouse was a bright, new star promising great success, her 'misdemeanours' were minimalised by the press and news stories focused on her music. Just several months and a few missed gigs later paparazzi shots of Winehouse inebriated in public dominated. Perhaps the most damning story was The Sun's publication of a video of Winehouse allegedly smoking crack cocaine in January 2008. Even though stories in the preceding summer had described Winehouse as a "tortured soul” (A10), this seemed to be the turning point when media coverage stopped mentioning her musical prowess altogether and focused solely on her relationship with drugs.

Anyway, here she goes, as usual, from one crisis to the next. And all the crises are the same. It isn't harrowing, it’s boring. (A14)

The pictures last year of her wandering the streets, confused and desperate, in blooded ballet pumps were genuinely shocking; then one could feel sorry for her . . . Several months on she's still shambling about and patience is wearing thin. (A34)

\section{Glamorization or gritty realism?}

The third theme concerns an ambivalence that runs throughout both the press and focus group data around the perennial theme of to what extent media can be held responsible for the effect on their readers. Chiefly this ambivalence concerns whether stories of drug-taking excess are simple reflections of contemporary reality and therefore fulfilling

Final version of published article: Shaw, R.L., Whitehead, C. \& Giles, D.C. (2010). "Crack down on celebrity junkies": does media coverage of celebrity drug use pose a risk to young people? Health, Risk \& Society, 12(6), 575-589. 
an informative or educational function, or glamorized fictions, exaggerations or caricatures which fulfil a crude, and potentially harmful, entertainment function.

Some press articles emphasised the 'let-this-be-a-lesson-to-you' function of coverage of wasted celebrity:

Photographed emaciated, bruised and bleeding, weeping over her jailbird husband, slurring on stage, cancelling shows, her closely (and salaciously) documented journey from pop princess to barely functioning addict seems more like a cautionary tale. (A29)

Others, meanwhile, preferred to dwell on the apparent leniency offered to celebrity misdemeanour:

Being a celebrity is the equivalent to a Get Out of Jail Free card. (A35)

That loud, clear message was proclaimed all over again: Do drugs and you'll be cool, desirable and there'll be no penalty to pay. (A22)

The focus group participants expressed similar ambivalence. Some discussed the possibility that the coverage of Winehouse in states of disrepair following excessive drug use may actually dissuade such behaviour in newspaper readers rather than encourage it. In doing so, they drew frequently on discourses circulated in the social science tradition, for example, the notion of desensitization:

\footnotetext{
Alex: $\quad$ Yeah like the media has desensitised people to it haven't they 'cause it's always in the paper like 'oh someone's taken cocaine okay that doesn't matter anymore'

Adam: Yeah I see what you mean

Mazy: It's less of a shock isn't it? (FG1)
}

However, this position was not unanimous. Others were more likely to view the media coverage as sensational:

Sam: $\quad$ They just put it in the media like as in 'Woah!' Amy Winehouse again front page, couple of days later Amy Winehouse, Pete Doherty, it’s just glamorizing it it's not making it look bad

SJ: They do make it look rank [unpleasant] though. I don't want to look like Pete Doherty and Pete Doherty has no money, Amy Winehouse's husband is in prison, how is that glamorizing it?

Bruce: It's glamorizing it in the media as it's on the front page

Sam: Does it show what drug taking is? Does it show other people what they get if they take drugs? No it doesn't. How is it acceptable? (FG4)

Final version of published article: Shaw, R.L., Whitehead, C. \& Giles, D.C. (2010). "Crack down on celebrity junkies": does media coverage of celebrity drug use pose a risk to young people? Health, Risk \& Society, 12(6), 575-589. 
This extract is interesting because it demonstrates the differences of opinion within the group. Sam argues that the media do glamorize drug taking by not portraying its negative consequences while SJ puts the case that the press coverage does make it look unpleasant (“rank”) with consequences including incarceration. Nevertheless, as in the press, there was a sense among the focus groups that celebrities like Winehouse are a protected species beyond the law:

Anyone else would be in prison for doing drugs so much by now. (Alex; FG1)

But it’s like another rule for celebrities do you know what I mean? (JD; FG2)

These young people were all too aware of the illegality of drug use and the lack of legal action against Winehouse had not gone unnoticed.

\section{Discussion}

This paper has reported a media framing analysis of representations in the news media of Amy Winehouse's drug use and young people’s assessments of those media and Winehouse herself. We identified three dominant 'frames' that characterised the media coverage during the selected period and these were analysed alongside the talk of the young people in the discussion groups. Our findings revealed that these young people did not take the media coverage at face value. Instead they assessed the content of stories presented and considered the possibility that Winehouse may be actively involved in creating this media hype, thereby rejecting her assumed naïveté in the earlier articles in this sample. These young people have therefore challenged the mythmaking power of media by rejecting Winehouse as an unsuitable role model in a way that would not be predicted from either social learning theory or cognitive priming.

Final version of published article: Shaw, R.L., Whitehead, C. \& Giles, D.C. (2010). "Crack down on celebrity junkies": does media coverage of celebrity drug use pose a risk to young people? Health, Risk \& Society, 12(6), 575-589. 
Fears of 'media effects' in terms of modelling may continue to inform media content itself but this analysis reassures us that young audiences are able to read about celebrities like Winehouse with a critical eye.

Having said this, there is a possibility that the young people were simply reproducing discourses circulated in the media. As the Media Framing Analysis showed, the media coverage was far from consistent and later articles soon began to portray a loss of patience with Winehouse represented as a lost cause. The focus groups were conducted after these negatively framed stories of Winehouse had been published so it could be that the young people taking part were influenced by the press coverage. This would imply that social learning is still taking place, but from informational sources (if we can classify tabloid newspapers in such a way) rather than the celebrities themselves. Certainly the young people in this sample were clear that Winehouse was not someone they admired or identified with. This may result partly from the protective and moralising aspect of media coverage of Winehouse, a possibility that could be explored through interviews with older participants.

The criticism of Winehouse by the young people in our study contrasts sharply with the result of the Sky poll conducted only a few months before our focus groups (NME, 2008), that Winehouse was the "ultimate heroine” among people aged under 25. The young people in our study were unimpressed by her apparent inability to cope with what they described as a rock-n-roll lifestyle especially as it was at the expense of her talent; they felt that a musician should be famous for their music rather than their illicit drug use. Nevertheless, there were mixed opinions as to the merits of Winehouse's music. There was a tendency to contrast her unfavourably with rock 'greats', even those with their own histories of drug use, who were believed to be able to "make good music” despite being "on drugs”, one participant even citing Jimi Hendrix as an Final version of published article: Shaw, R.L., Whitehead, C. \& Giles, D.C. (2010). "Crack down on celebrity junkies": does media coverage of celebrity drug use pose a risk to young people? Health, Risk \& Society, 12(6), 575-589. 
exemplar (who in fact died from inhaling his own vomit during a heroin overdose). The distancing effect of the rock 'canon' suggests that even teenagers now buy into a discourse that privileges 'classic' artists at the expense of contemporary ones, even in the field of popular music.

While social learning theory does not seem to capture the psychological processes by which the young people in our study engage with Amy Winehouse, they clearly have built up some kind of parasocial relationship with her (Giles, 2002). Indeed, the findings of this study are consistent with recent research on parasocial relationships; although Winehouse herself was not one of the most unpopular celebrities, Giles and Newbold (under review) found that young women in particular often have an active dislike of 'controversial' female celebrities. It seems that media audiences, including apparently ‘impressionable’ young ones, are becoming increasingly critical of 'valueless' celebrity. Nevertheless, as the young people in our focus groups argued, Winehouse’s behaviour might earn her press coverage (and possibly extra record sales, although this link is almost impossible to ascertain) and it might contribute to her endurance as a music legend with the current teenage generation.

It would appear that concern about the influence of drug-taking celebrities, voiced even by bodies as powerful as the United Nations, may be somewhat overstated. Nevertheless, our findings illustrate that we do not yet fully understand young people’s relationship with the media. Firstly, the young participants did not count Winehouse as a role model, which poses problems for social learning theory; and they were sceptical about her own involvement in creating the media hype witnessed, which displayed media literacy and confirmed a more complex interaction than the media effects hypothesis would propose; but they may still have been influenced by the negative Final version of published article: Shaw, R.L., Whitehead, C. \& Giles, D.C. (2010). "Crack down on celebrity junkies": does media coverage of celebrity drug use pose a risk to young people? Health, Risk \& Society, 12(6), 575-589. 
framing of Winehouse observed in the later articles we sampled. Furthermore, there always remains the possibility that romanticised portrayals of drug use might penetrate young people's frame of reference during this particularly vulnerable stage of early development as a young adult, if only to circulate discourses of pleasure and abandon that make drug use seem appropriate in specific contexts (Hutton, 2004). In terms of the parasocial relationships built up through media use, Amy Winehouse is regarded by the young people in our study as a rather unimpressive figure, whose music harks back to a 'classic' era, but whose behaviour is more typical of worthless contemporary celebrity culture. She is perhaps, for them, a promising young person who has 'gone off the rails'. This is not altogether different from the identification invited by the media, whose frequent references to the Winehouse family, and to former rock stars, in their exhortation to "save Amy" have cast her as a tragic figure at the mercy of malicious external forces. It reinforces the impression that parasocial relationships do not emerge through the simple act of modelling but out of the framing process itself. Rather than 'blindly' imitating Winehouse because of her fame (or infamy), these accounts have revealed critical thinking skills and complex interactions between these young people and the ways in which mediated messages about drug use are framed.

Perhaps a better understanding of the connection could be arrived at through studying youth media (TV, magazines, social network sites and websites) rather than the print media. Nevertheless, this study gives us important insight into the level of critical awareness young people have when dealing with mediated stories of risk. We have also challenged some of the assumptions about the dangers of celebrity drug use by studying more intensively the reception of media coverage and the ways in which young people themselves relate to and make sense of media. These findings point toward the significance of critical media skills in education and the possibility that they Final version of published article: Shaw, R.L., Whitehead, C. \& Giles, D.C. (2010). "Crack down on celebrity junkies": does media coverage of celebrity drug use pose a risk to young people? Health, Risk \& Society, 12(6), 575-589. 
may contribute to drugs awareness programmes, such as FRANK

(http://www.talktofrank.com/), online resource with media campaigns including

television and cinema adverts, billboards and fliers. Finally, by examining both cultural material and talk about celebrity drug use, this study has highlighted the need for future work to delve more deeply into the complex processes at work in interpreting media influence on contemporary 'media literate' youth and its implications for understanding health risk behaviours.

Acknowledgements

We would to thank the participants for taking part and also Aston University who sponsored this research.

\section{References}

Anderson, C.A., Carnagey, N.L., and Eubanks, J. (2003). Exposure to violent media: The effects of songs with violent lyrics on aggressive thoughts and feelings. Journal of Personality and Social Psychology, 84, 960-971.

Bandura, A., Ross, D. and Ross, S.A. (1961). Transmission of aggression through imitation of aggressive models. Journal of Abnormal and Social Psychology, 63, $575-582$.

Bandura, A., Ross, D. and Ross, S.A. (1963). Imitation of film-mediated aggressive models. Journal of Abnormal Psychology, 66, 3-11.

Berkowitz, L. (1984). Some effects of thoughts on the anti- and prosocial influences of media events: A cognitive neoassociationistic analysis. Psychological Bulletin, 95, 410-427.

Billig, M. (1987). Arguing and thinking: A rhetorical approach to social psychology. London: Sage.

Final version of published article: Shaw, R.L., Whitehead, C. \& Giles, D.C. (2010). "Crack down on celebrity junkies": does media coverage of celebrity drug use pose a risk to young people? Health, Risk \& Society, 12(6), 575-589. 
Boon, S.D. and Lomore, C.D. (2001). Admirer-celebrity relationships among adults: explaining perceptions of celebrity influence on identity. Human Communication Research, 27, 432-465.

Braun, V. and Clarke, V. (2006). Using thematic analysis in psychology. Qualitative Research in Psychology, 3, 77-101.

Brown, W.J., Basil, M.D., and Bocarnea, M.C. (2003). Social influence of an international celebrity: Responses to the death of Princess Diana. Journal of Communication, 53(4), 587-605.

Bryant, J., and Zillmann, Z. (2002). Media effects: Advances in theory and research (2 ${ }^{\text {nd }}$ edn.) . Hillsdale, NJ: Lawrence Erlbaum Associates.

Cooper, C.P., and Yukimura, D. (2002). Science writers’ reactions to a medical “breakthrough” story. Social Science \& Medicine, 54, 1887-1896.

Donnelly, L.S., Shaw, R.L. and van den Akker, O.B.A. (2008). eHealth as a challenge to 'expert' authority: a focus group study of internet use for health information and management. Journal of the Royal Society of Medicine, 101, 501-506.

Entman, R. M. (1993). Framing: Towards clarification of a fractured paradigm. Journal of Communication, 43, 51-58.

Fernández, J.G.F. (2003). Musica y drogodependencias: Análisis de algunos tópicos sobre drogas encontrados en la música. Adicciones, 15, 229-242.

Forsyth, A., and Barnard, M. (1998). Relationships between popular music and drug use among Scottish schoolchildren. International Journal of Drug Policy, 9, 125-132.

Gamson, W. and Modigliani, A. (1989). Media discourse as a symbolic contest: a constructionist approach. American Journal of Sociology, 95, 1-37.

Gauntlett, D. (2005). Moving experiences: Media effects and beyond ( $2^{\text {nd }}$ edn.).

Final version of published article: Shaw, R.L., Whitehead, C. \& Giles, D.C. (2010). "Crack down on celebrity junkies": does media coverage of celebrity drug use pose a risk to young people? Health, Risk \& Society, 12(6), 575-589. 
Giles, D.C. (2002). Parasocial interaction: A review of the literature and a model for future research. Media Psychology, 4, 279-302.

Giles, D.C., and Newbold, J.C. (under review). Exploring parasocial relationships.

Giles, D.C., and Shaw, R.L. (2009). The psychology of news influence and the development of Media Framing Analysis. Social and Personality Psychology Compass, 3/4, 375-393.

Greitemeyer, T. (2009). Effects of songs with prosocial lyrics on prosocial thoughts, affect, and behaviour. Journal of Experimental Social Psychology, 45, 186-190.

Hawkes, G., Houghton, J. and Rowe, G. (2009). Risk and worry in everyday life: comparing diaries and interviews as tools in risk perception research. Health, Risk \& Society, 11(3), 209-230.

Hutton, F. (2004). Up for it, mad for it? Women, drug use and participation in club scenes. Health, Risk \& Society, 6(3), 223-237.

International Narcotics Control Board (2008). 2007 annual report. United Nations Publications.

Kitzinger, J. (2000). Media templates: Patterns of association and the (re)construction of meaning over time. Media, Culture \& Society, 22, 61-84.

Knobloch-Westerwick, S., Musto, P., and Shaw, K. (2008). Rebellion in the top music charts: Defiant messages in rap/hip-hop and rock music 1993 and 2003. Journal of Media Psychology, 20, 15-23.

Markert, J. (2001). Sing a song of drug use-abuse: Four decades of drug lyrics in popular music: From the Sixties through the Nineties. Sociological Inquiry, 71, 194220.

Final version of published article: Shaw, R.L., Whitehead, C. \& Giles, D.C. (2010). "Crack down on celebrity junkies": does media coverage of celebrity drug use pose a risk to young people? Health, Risk \& Society, 12(6), 575-589. 
Martin, G., Clarke, M., and Pearce, C. (1993). Adolescent suicide: music preference as an indicator of vulnerability. Journal of the American Academy of Child and Adolescent Psychiatry, 32, 530-535.

Miranda, D., and Claes, M. (2004). Rap music genres and deviant behaviours in FrenchCanadian adolescents. Journal of Youth and Adolescence, 33, 113-122.

NME (2008). Amy Winehouse voted top heroine for UK youths. NME news, 23 April 2008. Retrieved 31 March 2009 from http://www.nme.com/news/amywinehouse/36117.

Primack, B.A., Dalton, M.A., Carroll, M.V., Agarwal, A.A. and Fine, M.J. (2008). Content analysis of tobacco, alcohol, and other drugs in popular music. Archives of Pediatrics \& Adolescent Medicine, 162(2), 169-175.

Shaw, R.L. and Giles, D.C. (2009). Motherhood on ice? A media framing analysis of older mothers in the UK news. Psychology \& Health, 24(2), 221-236.

Wilkinson, S. (2008). Focus groups. In J.A. Smith (Ed.), Qualitative psychology: a practical guide to research methods (pp. 186-206). London: Sage.

Final version of published article: Shaw, R.L., Whitehead, C. \& Giles, D.C. (2010). "Crack down on celebrity junkies": does media coverage of celebrity drug use pose a risk to young people? Health, Risk \& Society, 12(6), 575-589. 
Table 1: Newspaper articles about Amy Winehouse’s drug use

\begin{tabular}{|c|c|c|c|}
\hline Number & Date & Paper & Title \\
\hline 1. & 22.07 .07 & The Observer & $\begin{array}{l}\text { Amy Winehouse: Dive driven by her demons: missed gigs, drunken antics and that beehive 'do - it comes as } \\
\text { little surprise that the soulful songstress from north London is a gossip column fixture. But her rock'n'roll } \\
\text { lifestyle sits along a vast musical talent. }\end{array}$ \\
\hline 2. & 23.07 .07 & The Guardian & Hard times for Amy Winehouse, Britain's biggest female star \\
\hline 3. & 03.08 .07 & Daily Mail & We're Mr and Mrs Normal! \\
\hline 4. & 04.08 .07 & Daily Star & Hard drinking, beehived rock ‘n’ roll hell raiser Amy Winehouse tells why she’s still Daddy’s little girl \\
\hline 5. & 09.09 .07 & The Mirror & Go to Rehab; exclusive friends urge troubled star to get help after she collapses \\
\hline 6. & 10.08 .07 & $\begin{array}{l}\text { The Daily } \\
\text { Telegraph }\end{array}$ & Amy, Don’t become a car crash rock star. \\
\hline 7. & 11.08 .07 & Daily Mail & $\begin{array}{l}\text { Cocaine, ecstasy even horse tranquillizers. As singer Amy Winehouse finally checks into rehab after } \\
\text { collapsing this week, can any one save her from self-destruction? }\end{array}$ \\
\hline 8. & 17.08 .07 & The Guardian & $\begin{array}{l}\text { Amy Winehouse: She has had her troubles but she has been catapulted to being a superstar... the thing is she } \\
\text { absolutely can deliver: is rehab after an overdose finally making the talented singer alter her lifestyle? }\end{array}$ \\
\hline 9. & 19.08 .07 & Mail on Sunday & $\begin{array}{l}\text { Exclusive: Mother of soul diva Amy Winehouse explains, in heart breaking detail, why she feels powerless } \\
\text { to stop her troubled daughters descent into hell of addiction }\end{array}$ \\
\hline
\end{tabular}

Final version of published article: Shaw, R.L., Whitehead, C. \& Giles, D.C. (2010). “Crack down on celebrity junkies”: does media coverage of celebrity drug use pose a risk to young people? Health, Risk \& Society, 12(6), 575-589. 


\begin{tabular}{|c|c|c|c|}
\hline 10. & 01.09 .07 & Financial Times & Tortured soul women in the news - Amy Winehouse \\
\hline 11. & 04.12 .07 & Daily Mail & Why isn't anyone saving Amy? \\
\hline 12. & 09.12 .07 & $\begin{array}{l}\text { News of the } \\
\text { World }\end{array}$ & I long to wrap you in my arms... you are still my baby \\
\hline 13. & 24.01 .08 & The Times & Why Amy's on the rocks \\
\hline 14. & 24.01 .08 & The Express & Amy, just disappear in a puff of smoke \\
\hline 15. & 25.01 .08 & Daily Post & Troubled singer goes into rehab \\
\hline 16. & 26.01 .08 & The Express & Someone has to save Amy from her Demons \\
\hline 17. & 27.01 .08 & The Observer & Yes, she's a mess - so why do we teenagers still love Amy? \\
\hline 18. & 13.02 .08 & The Sun & Drug-addled Amy should not be a role model \\
\hline 19. & 17.02 .08 & Sunday Express & Keith Richards: Don't do drugs Amy \\
\hline 20. & 05.03 .08 & Daily Mail & Tame the cocaine stars; Giving drug-taking celebrities an easy ride sends wrong message, says UN \\
\hline 21. & 06.03 .08 & The Sun & $\begin{array}{l}\text { UN chiefs have accused celebs such as Amy Winehouse of fuelling the UK’s cocaine culture by } \\
\text { glamourising drugs }\end{array}$ \\
\hline 22. & 06.03 .08 & Daily Star & Crack down on the celeb junkies \\
\hline 23. & 06.03 .08 & Daily Star & $\begin{array}{l}\text { When white powder was just for washing. Picture exclusive: fresh faced Amy Winehouse before the drugs } \\
\text { took their toll }\end{array}$ \\
\hline
\end{tabular}

Final version of published article: Shaw, R.L., Whitehead, C. \& Giles, D.C. (2010). “Crack down on celebrity junkies”: does media coverage of celebrity drug use pose a risk to young people? Health, Risk \& Society, 12(6), 575-589. 


\begin{tabular}{|c|c|c|c|}
\hline 24. & 07.03 .08 & Yorkshire Post & Fame and misfortune - why we're addicted to celeb culture \\
\hline 25. & 17.03 .08 & The Sun & Drug stars snort above the law \\
\hline 26. & 09.03 .08 & The Observer & Coke fashionistas' are ruining Africa - UN boss \\
\hline 27 & 09.03 .08 & Sunday Mirror & Sort yourself out, Amy... We're losing patience \\
\hline 28 & 10.03 .08 & Daily Mail & The celebrity junkies’ trail of misery, by UN drug chief \\
\hline 29. & 13.03 .08 & $\begin{array}{l}\text { The Daily } \\
\text { Telegraph }\end{array}$ & $\begin{array}{l}\text { Is Amy really the poser girl for drug abuse? The UN's drug tsar has singled out the troubled singer for } \\
\text { criticism. Neil McCormick is unconvinced }\end{array}$ \\
\hline 30. & 16.04 .08 & The Sun & Amy given album ultimatum \\
\hline 31. & 24.04 .08 & Daily Star & We Give up. \\
\hline 32. & 26.04 .08 & Daily Mail & Can Amy sink any lower? \\
\hline 33. & 27.04 .08 & $\begin{array}{l}\text { The Independent } \\
\text { on Sunday }\end{array}$ & For God's sake, Amy, its time to get a grip. \\
\hline 34. & 27.04 .08 & The Observer & Amy was brilliant. Now she’s a bore \\
\hline 35. & 17.05 .08 & The Sun & Amy Winehouse \\
\hline
\end{tabular}

Final version of published article: Shaw, R.L., Whitehead, C. \& Giles, D.C. (2010). “Crack down on celebrity junkies”: does media coverage of celebrity drug use pose a risk to young people? Health, Risk \& Society, 12(6), 575-589. 